\title{
Parental Correlates of Body Weight Status Among High School Students in Tehran
}

\author{
Sara Jalali-Farahani, ${ }^{1,2}$ Yit Siew Chin,,${ }^{2,3,}{ }^{*}$ Mohd Nasir Mohd Taib, ${ }^{2,3}$ and Parisa Amiri ${ }^{1}$ \\ ${ }^{1}$ Research Center for Social Determinants of Endocrine Health and Obesity Research Center, Research Institute for Endocrine Sciences, Shahid Beheshti University of Medical \\ Sciences, Tehran, Iran \\ ${ }^{2}$ Department of Nutrition and Dietetics, Faculty of Medicine and Health Sciences, Universiti Putra Malaysia, Serdang, Selangor Darul Ehsan, Malaysia \\ ${ }^{3}$ Research Center of Excellence Nutrition and Non communicable Diseases, Faculty of Medicine and Health Sciences, Universiti Putra Malaysia, 43400 UPM, Serdang, \\ Selangor, Malaysia \\ "Corresponding author: Yit Siew Chin, Department of Nutrition and Dietetics, Faculty of Medicine and Health Sciences, Universiti Putra Malaysia, Serdang, Selangor Darul \\ Ehsan, Malaysia. Tel: +603-89472680, Fax: +603-89426769, E-mail: chinys@upm.edu.my
}

Received 2016 October 03; Revised 2017 January 30; Accepted 2017 April 03.

\begin{abstract}
This study aimed to determine the parental correlates of body weight status among adolescents in Tehran. The participants were 465 high school students and their parents who resided in Tehran. Body weight and height of the students were measured, and body mass index (BMI)-for-age and body weight status of the students were determined according to the world health organization growth reference (2007). Parents of the students completed a self-administered questionnaire including socio-demographic information, self-reported parental body weight and height, and parental perception of student's body weight status. About half of the parents had an incorrect perception about body weight status of their children with higher rates of underestimation than overestimation. The percentage of parents who correctly perceived body weight status of the students decreased from $100.0 \%$ in severe thinness group to $14.0 \%$ in obese group. There were no significant associations between marital status, occupation, and education of parents and BMI-for-age of the students. While, both BMI of mother and BMI of father were significantly associated with students' BMI-for-age $(r=0.29$ and $r=0.27$, respectively; $\mathrm{P}<0.05)$. A great number of parents had incorrect perception regarding body weight status of their offspring; this was true specifically for parents of overweight and obese students. Both parental BMI and parental perception regarding students' body weight status were associated with students' BMI-for-age, indicating the need for parental involvement in weight management programs targeting adolescents.
\end{abstract}

Keywords: Adolescents, Parents, Socio-demographic Factors, Parental BMI, Parents' perception

\section{Background}

Similar to other parts of the world, overweight and obesity are relatively prevalent among Iranian children and adolescents. According to recent findings from a national survey of representative sample of Iranian students, more than one in five of Iranian school children were found to be overweight and obese (1). A wide range of negative health outcomes (2-4) as well as poor healthrelated quality of life (5) has been linked to adolescence obesity. Furthermore, being overweight and obese in adolescence increases the likelihood of remaining overweight and obese in adulthood (6). Many factors have been shown to be associated with adolescent obesity, and parental factors were demonstrated to be important determinants.

Previous studies reported parental influences on overweight and obesity during adolescence; for instance, maternal employment, parental marital status, parental education as well as parental overweight and obesity were among the factors that associated with overweight and obesity in adolescents (7-10). Furthermore, mother's employment was found to be among the factors that affect obesity in adolescence (8) and more working hours of mother was found to increase the risk of obesity among children (11). In addition, findings of another study on 7,908 adolescents (aged 11 - 19 years) in Iran suggested that parental overweight and obesity, parental education, and paternal occupation were major parental determinants of overweight and obesity, and higher parental education was associated with overweight and obesity in adolescents (9).

Additionally, the perception of parents regarding body weight status of adolescents is another factor found to be associated with overweight and obesity. There are numerous studies demonstrating that parents tend to misperceive the body weight status of their children (12-16). In this regard, higher percentage of mothers of overweight and obese adolescents incorrectly perceived body weight status of their children compared to mothers of normal-weight adolescents; and misclassification of body weight status was more common in parents of overweight and obese adolescents compared to their normal-weight counterparts (13,15-17). Parental conversation, supporting, 
and role-modeling may have an influence on adolescents' food choices, eating behaviors, and physical activity (18-21); hence, how parents perceive adolescents' body weight status and its related behaviors may contribute to weight gain and consequently obesity among adolescents.

Considering rising trend of overweight and obesity reported in adolescents in Tehran (22) and the important role of parents in success of weight management programs (23), it is important to determine which parental factors are mostly associated with overweight and obesity.

\section{Objectives}

This study aimed to investigate the association between parental factors and overweight/obesity in high school students in Tehran.

\section{Methods}

The participants of this study were 465 high school students (aged 14 - 17 years) and their parents who resided in Tehran. Using multi-stage sampling method, the students were selected from six high schools located in three diverse geographical zones (North, Center, and South) in Tehran. Further details on sampling method have been presented previously (24). Ethical approvals were obtained from medical research ethics committee of the faculty of medicine and health sciences, Universiti Putra Malaysia (UPM) and the research institute for endocrine sciences of Shahid Beheshti University of Medical Sciences in Iran. Both parents and the students who agreed to participate in the study were asked to sign consent forms. Body weight and height of the students were measured by trained individuals. Body mass index-for-age (BMI Z-score) was calculated using AnthroPlus software (version 3.2.2). After determining BMI-for-age of each student, body weight status of the students was determined based on the world health organization (WHO) growth reference (2007). Based on BMIfor-age, the students were classified into five groups, including $<-3$ SD as severe thinness, $\geq-3$ SD to $<-2$ SD as thinness, $\geq-2$ SD to $\leq 1$ SD as normal weight, $>1$ SD to $\leq 2$ SD as overweight, and $>2$ SD as obesity.

To obtain parental information, the students were asked to deliver a self-administered questionnaire to their parents. The parents supposed to complete the questionnaires and return them back to the researchers by the students. The questionnaire consisted of information regarding socio-demographic information, self-reported parental body weight and height, and parental perception of student's body weight status. A high percentage of the parental questionnaires were completed by mothers (76.3\%) and the rest was mostly completed by fathers (22.8\%).

In the socio-demographic information section, the parents gave information on age, gender, and school year of the students. Moreover, the parents provided information about their marital status, occupation, and education level. Additionally, both fathers and mothers were asked to report their current body weight and height. The body mass index (BMI) of parents was calculated as weight in kilograms, divided by height in meters squared. To determine body weight status of parents, parental BMI was classified into four main groups according to Centres for disease control and prevention (CDC) cut-off. Parental BMI less than 18.5 was classified as underweight, between 18.5 and 24.9 as normal weight, between 25 and 29.9 as overweight, and 30 or higher was classified as obese.

Besides, to obtain parental perception regarding studen's body weight status, parents were asked to answer a simple question: "How do you perceive the current body weight status of your child?" Parents chose their answer from five choices including severe thinness, thinness, normal weight, overweight, and obese. To assess whether parents correctly or incorrectly perceive the student's body weight status, parental perception of student's body weight status was compared with actual body weight status of the student. The result of comparison between parental perception of student's body weight status and actual body weight status of student were categorized into three groups including under-estimator, correct-estimator, and over-estimator. Correct-estimation was defined when both parental perceptions of student body weight status and actual body weight status of student were similar. Under-estimation was defined when parent categorized the student to a lower body weight status group compared to the actual body weight status of the student. Over-estimation was defined when parent categorized the student to a higher body weight status group compared to the actual body weight status of the student. Over-estimator and under-estimator were further regrouped into incorrect estimator.

Descriptive statistics including mean and standard deviation for continuous variables and frequency and percentage for categorical variables were reported. To compare mean values of continuous variables between two groups, independent sample t-test was used. To compare mean values of continuous variables among more than two groups, one-way analysis of variance (ANOVA) was applied. To determine the correlations between two continuous variables, Pearson product-moment correlation was employed. Sensitivity and specificity for parental perception of students' body weight status were defined as true 
positive rate (true positives/true positives + false negatives) and true negative rate (true negatives/true negatives + false positives), respectively, determined for each body weight status group according to WHO definition. The SPSS software (version 19.0) was used for analyzing data and $P$ value of less than 0.05 was considered as statistically significant.

\section{Results}

The mean age of the students was $15.56 \pm 0.94$ years. Socio-demographic characteristics of the students are presented in Table 1. Most of the students were from twoparent families (94.4\%), and a few of them (5.6\%) were from single-parent families. In terms of educational level of parents, more than half of the mothers (57.2\%) had high school diploma, and about one-fourth of them (24.8\%) had a university degree. Approximately half of the fathers (47.0\%) had high school diploma, and about one-third of them (34.5\%) had a university degree. As for occupation of parents, most of the mothers were housewives (81.9\%) and about one-fifth $(18.1 \%)$ of them were working outside the home. Most of the fathers were employed or self-employed (87.6\%). The percentage of jobless, laborer, and retired fathers was $1.2 \%, 2.7 \%$, and $8.5 \%$, respectively.

The mean BMI and body weight status of parents are presented in Table 2. About two-third of the mothers (64.3\%) were overweight and obese, 35.5\% were normalweight, and $0.2 \%$ were underweight. Similarly, about twothird of fathers were found to be overweight or obese (67.6\%), 31.9\% were normal-weight, and $0.5 \%$ of fathers were underweight.

The mean BMI values of the students were $23.04 \pm$ $4.92 \mathrm{~kg} / \mathrm{m}^{2}$ and $23.08 \pm 5.08 \mathrm{~kg} / \mathrm{m}^{2}$ in girls and boys, respectively. Figure 1 shows the distribution of students according to their actual body weight status using the WHO (2007) cut-off and parental perception of the student's body weight status. Based on actual body weight of the students, $0.4 \%$ were severely thin, $2.4 \%$ were thin, $58.7 \%$ were normal-weight and more than one-third of the students (38.5\%) were overweight or obese (24). However, based on parental perception of student's body weight status, a total of $2.9 \%$ were severely thin, $15.6 \%$ were thin, $54.9 \%$ were normal weight, and about one-fourth of them (26.6\%) were overweight or obese.

As a whole, in the current study, about half of the parents had incorrect perception about student's body weight status. Also, $56.5 \%$ of the parents correctly estimated, $40 \%$ under-estimated, and $3.5 \%$ over-estimated the body weight status of their children. Considering both parental overestimation and underestimation of the students' body weight status, the overall percentage of incorrect parental perception of the student's body weight status was $43.5 \%$.

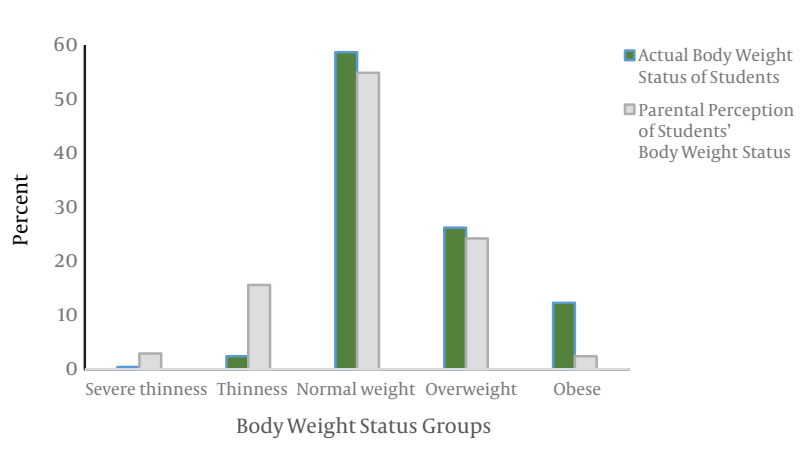

Figure 1. Percentages of Students in Body Weight Status Groups According to Actual Body Weight Status of the Students and Parental Perception of Students' Body Weight Status

Table 3 represents the percentage of correct and incorrect parental perception of student's body weight status in each category of body weight status (correct percentages presented as bold numbers). Additionally, when body weight of the students increased, the percentage of correct parental perception of the student's body weight status decreased (Table 3). As shown in Table 3, the percentage of correct parental perception decreased from $100 \%$ in the severe thinness group to $14.0 \%$ in the obese group.

The mean BMI-for-age of the students was not significantly different in students from two-parent families than those from single-parent families $(0.49 \pm 1.36$ vs. $-0.05 \pm$ 1.38 , respectively; $\mathrm{t}=-1.93, \mathrm{P}=0.06$ ). In terms of occupation of parents, the mean BMI-for-age values were $0.47 \pm$ 1.39 and $0.46 \pm 1.23$ in students whose mothers were housewives and those whose mothers were working outside the home, respectively. The mean BMI-for-age values of the students were not significantly different between the aforementioned groups $(\mathrm{t}=0.06, \mathrm{P}=0.95)$. Also, the results of one-way ANOVA test showed that the mean of student's BMI-for-age was not significantly changed by occupation of fathers. Besides, the years of education completed by mothers and fathers were not significantly correlated with student's BMI-for-age ( $\mathrm{r}=0.02, \mathrm{P}=0.65$ and $\mathrm{r}=0.06, \mathrm{P}=$ 0.20 , respectively).

In terms of BMI of parents, BMI of the mothers was significantly correlated with student's BMI-for-age $(r=0.29$, $\mathrm{P}<0.05$ ). Similarly, BMI of the fathers was significantly correlated with student's BMI-for-age $(r=0.27, P<0.05)$. In other words, higher BMI values of mothers and fathers were correlated with higher BMI-for-age in students, indicating that students with overweight and obese parents were more likely to be overweight and obese.

The mean BMI-for-age of the students was significantly higher in students whose parents incorrectly perceived their body weight status $(0.69 \pm 1.55)$ than students whose 
Table 1. Socio-Demographic Characteristics of the Students by Sex

\begin{tabular}{|c|c|c|c|}
\hline & Boys $(\mathbf{n}=\mathbf{2 3 8})$ & Girls $(\mathbf{n}=\mathbf{2 2 7})$ & Total $(n=465)$ \\
\hline \multicolumn{4}{|c|}{ Caregiver who completed parental questionnaire $(n=464)$} \\
\hline Mother & $153(64.6)^{\mathrm{a}}$ & $201(88.5)$ & $354(76.3)$ \\
\hline Father & $81(34.2)$ & $25(11.0)$ & $106(22.8)$ \\
\hline Other & $3(1.2)$ & $1(0.4)$ & $4(0.8)$ \\
\hline \multicolumn{4}{|l|}{ Marital status of parent $(n=464)$} \\
\hline Married & $225(95.0)$ & $213(93.8)$ & $438(94.4)$ \\
\hline Divorced & $6(2.5)$ & $7(3.1)$ & $13(2.8)$ \\
\hline Widowed & $6(2.5)$ & $7(3.1)$ & $13(2.8)$ \\
\hline \multicolumn{4}{|l|}{ Educational level of mothers $(n=460)$} \\
\hline Less than high school diploma & $42(17.8)$ & $41(18.2)$ & $83(18.0)$ \\
\hline High school diploma & $133(56.6)$ & $130(57.9)$ & $263(57.2)$ \\
\hline University degrees & $60(25.6)$ & $54(23.9)$ & $114(24.8)$ \\
\hline \multicolumn{4}{|l|}{ Educational level of fathers $(n=447)$} \\
\hline Less than high school diploma & $35(15.4)$ & $48(21.9)$ & $83(18.5)$ \\
\hline High school diploma & $102(44.7)$ & $108(49.3)$ & $210(47.0)$ \\
\hline University degrees & $91(39.9)$ & $63(28.8)$ & $154(34.5)$ \\
\hline \multicolumn{4}{|l|}{ Working status of mothers $(n=432)$} \\
\hline Housewife & $186(83.4)$ & $168(80.4)$ & 354 (81.9) \\
\hline Working outside the home & $37(16.6)$ & $41(19.6)$ & $78(18.1)$ \\
\hline \multicolumn{4}{|l|}{ Job status of fathers $(n=412)$} \\
\hline Jobless & $3(1.4)$ & $2(1.0)$ & $5(1.2)$ \\
\hline Laborers & $6(2.8)$ & $5(2.5)$ & $11(2.7)$ \\
\hline Employed & $84(39.6)$ & $66(33.0)$ & $150(36.4)$ \\
\hline Self-employed & $102(48.1)$ & $109(54.5)$ & $211(51.2)$ \\
\hline Retired & $17(8.1)$ & $18(9.0)$ & $35(8.5)$ \\
\hline
\end{tabular}

${ }^{\mathrm{a}}$ Figures in parentheses denote percentages.

parents correctly perceived their body weight status (0.31 $\pm 1.17)(\mathrm{t}=2.89, \mathrm{P}<0.05)$. In other words, students whose parents incorrectly perceived their body weight status tended to have higher BMI-for-age compared to those whose parents correctly perceived their body weight status.

The sensitivity of parental perception of students' body weight status for detection of normal weight, overweight, and obesity was $0.69,0.63$, and 0.14 , respectively. The specificity of parental perception of students' body weight status for normal weight, overweight, and obesity was $0.66,0.96$, and 0.99, respectively.

\section{Discussion}

In the current study, about one-third of the students were overweight and obese (38.5\%). This is higher than the rates reported in previous studies conducted among adolescents in Tehran $(25,26)$. In a study conducted by Mohammadpour-Ahranjani et al. (2004) on 2,321 students (11 - 16 years-old) in Tehran, the overall prevalence of overweight and obesity using CDC cut-off was $28.9 \%$ (25). In another study conducted on 10-15 year-old students from the Sixth District of Tehran, the prevalence rates of overweight and obesity using the CDC cut-off were $25.5 \%$ and $27.0 \%$ in girls and boys, respectively (26). Comparing our results with previous findings indicates that the prevalence of overweight and obesity has increased over the years, which is consistent with results of Tehran Lipid and Glucose Study 
Table 2. Mean BMI and Distribution of Body Weight Status of the Parents

\begin{tabular}{|c|c|c|c|}
\hline & Boys & Girls & Total \\
\hline \multicolumn{4}{|c|}{ Mother's body weight status $(n=425)$} \\
\hline Underweight & $0(0.0)^{\mathrm{a}}$ & $1(0.5)$ & $1(0.2)$ \\
\hline Normal weight & $79(36.4)$ & $72(34.6)$ & $151(35.5)$ \\
\hline Overweight & $94(43.3)$ & $84(40.4)$ & $178(41.9)$ \\
\hline Obese & $44(20.3)$ & $51(24.5)$ & $95(22.4)$ \\
\hline Mother's BMI & $26.85 \pm 4.05$ & $27.21 \pm 4.18$ & $27.02 \pm 4.12$ \\
\hline \multicolumn{4}{|c|}{ Father's body weight status $(n=404)$} \\
\hline Underweight & $2(1.0)$ & $0(0.0)$ & $2(0.5)$ \\
\hline Normal weight & $66(31.6)$ & $63(32.2)$ & $129(31.9)$ \\
\hline Overweight & $101(48.6)$ & $102(52.0)$ & $203(50.3)$ \\
\hline Obese & $39(18.8)$ & $31(15.8)$ & $70(17.3)$ \\
\hline Father's BMI & $26.80 \pm 3.79$ & $26.79 \pm 3.41$ & $26.80 \pm 3.61$ \\
\hline
\end{tabular}

${ }^{\mathrm{a}}$ Figures in parentheses denote percentages.

Table 3. Comparison of Parental Perception of Students' Body Weight Status and Actual Body Weight Status of Students $(n=455)^{\mathrm{a}}$

\begin{tabular}{|c|c|c|c|c|c|}
\hline \multirow[t]{2}{*}{ Actual Body Weight Status of Students } & \multicolumn{5}{|c|}{ Parental Perception of Students' Body Weight Status } \\
\hline & Severe Thinness & Thinness & Normal Weight & Overweight & Obese \\
\hline Severe thinness & $100 \%$ & - & - & - & - \\
\hline Thinness & $9.1 \%$ & $\mathbf{8 1 . 8} \%$ & $9.1 \%$ & - & - \\
\hline Normal weight & $4.5 \%$ & $22.3 \%$ & 69.1\% & $4.1 \%$ & - \\
\hline Obese & - & $1.8 \%$ & $5.3 \%$ & $78.9 \%$ & $14.0 \%$ \\
\hline
\end{tabular}

${ }^{\mathrm{a}}$ In each row (body-weight group), bold numbers are percentage of correct estimates of student's body weight status by parents, the numbers appeared on the left and right sides of bold numbers are percentages of underestimates and overestimates by parents, respectively.

(TLGS) that revealed an increasing trend for overall prevalence of overweight and obesity from $19.0 \%$ to $32.2 \%$ (22).

According to the finding of the current study, about half of the parents (43.5\%) incorrectly perceived body weight status of their children. Moreover, more parents tended to underestimate rather than overestimate their children's body weight status (40.0\% vs. $3.5 \%$, respectively). Our finding is consistent with findings of previous studies that reported parental misperception regarding body weight status of their children (27-29). Similar to our finding, Aljunaibi et al. (2013) reported a higher level of underestimation (27.4\%) compared to overestimation (6.3\%) of children's weight status by parents. It is important for parents to have a correct perception regarding body weight status of their children; as it may affact weight loss in overweight and obese adolescents through supporting and promoting healthy lifestyle by parents (17).
Based on the results of this study, BMI-for-age of the students had no significant association with marital status of parents, occupation of parents, and number of years of education completed by parents. There are inconsistencies in findings of previous studies regarding the association between occupation and education level of parents and body weight status of offspring $(9,30-34)$. There are some studies that reported significant associations between occupation of father and BMI of Iranian adolescents $(9,34)$. On the other hand, consistent with our finding, a study conducted by Doustmohammadian et al. (2009) found no association between occupation of parents and BMI of adolescents. In terms of parental education, while some studies suggested that higher level of education of parents may play a protective role against obesity in offspring $(31,32)$, there are other studies reporting a direct relationship between parental education and obesity in adolescents $(9,33,34)$. 
On the other hand, both BMI of mothers and BMI of fathers were significantly associated with BMI-for-age of the students. This finding is consistent with results of previous studies conducted in different provinces of Iran $(9,33,34)$. In this context, both genetic and lifestyle factors may have an influence on the association between parental BMI and BMI of their offspring due to genetic resemblance and similarity of behavioral risk factors of family members (35).

Additionally, the current findings revealed that by increasing students' body weight, the percentage of correct perception of parents regarding students' body weight status decreased gradually. While $100 \%$ of parents of severely thin students correctly perceived their children's body weight status, this percentage reduced to $81.8 \%$ and 69.1\% for parents of thin and normal-weight students, respectively; meanwhile only $46.2 \%$ and $14.0 \%$ of parents of overweight and obese students correctly perceived their children's body weight status. Besides, the mean of student's BMI-for-age was significantly higher in a group of students whose parents incorrectly perceived their body weight status compared to another group of students whose parents correctly perceived their body weight status. These findings suggest that parents of overweight and obese students were more likely to misclassify body weight status of their offspring. The findings of the current study add to the body of evidence regarding poor ability of parents in correct estimation of body weight status of overweight and obese children $(28,29,36,37)$. Another study conducted on primary school children in Tehran also indicated that about one-third of mothers of obese children did not recognize obesity in their children (38). In a systematic review of 51 studies, Rietmeijer-Mentink et al. (2013) reported that the misperception of body weight status of overweight offspring by parents related to age of children as percentage of misperception of body weight status in young overweight children (2 - 6 years-old) was higher than that of older age groups. However, our findings showed that higher percentages of parents failed to recognize overweight and obesity in their offspring compared to mothers of primary school children as reported by Pakpour et al. (2011). Hence, it seems poor ability of parents in recognition of overweight and obesity is a concern among Iranian adolescents.

Similar to other studies, the limitations of this study need to be considered in the interpretation of the findings. Parental body weight and height were self-reported; hence, inaccurate estimation of body weight and height should be taken into consideration. Due to the cross-sectional nature of the current study, we can only conclude that parents of overweight and obese students were more likely to perceive incorrectly body weight status of their children. Hence, intervention studies are needed to inves- tigate whether improving parents' perception regarding body weight status of students can have an influence on weight loss in overweight and obese students. Next, household income data were not collected from the students in this study. Finally, the respondents of this study were limited to residents of Tehran; thus, the findings of this study cannot be generalized to other provinces of Iran. Hence, nationwide studies are recommended to depict better the parental correlates of body weight status of Iranian students.

In summary, the findings of this study imply the high prevalence of parental misperception regarding body weight status of their offspring; this is true specifically for parents of overweight and obese students. Both parental BMI and parental perception regarding students' body weight status were associated with students' BMI-for-age, indicating the need for parental involvement in weight management programs targeting adolescents.

\section{Acknowledgments}

The authors would like to acknowledge all school staff and participants who made this study possible.

\section{Footnotes}

Conflict of Interest: The authors declare that they have no conflict of interest.

Ethical Standard: All procedures performed involving human participants were in accordance with the ethical standards of the corresponding institutional and/or national research committees and with the 1964 Helsinki declaration and its later amendments or comparable ethical standards.

Informed Consent: Written informed consent forms were obtained from both students and their parents.

\section{References}

1. Kelishadi R, Ardalan G, Qorbani M, Ataie-Jafari A, Bahreynian M, Taslimi M, et al. Methodology and Early Findings of the Fourth Survey of Childhood and Adolescence Surveillance and Prevention of Adult Non-Communicable Disease in Iran: The CASPIAN-IV Study. Int J Prev Med. 2013;4(12):1451-60. [PubMed: 24498502].

2. Aronne LJ, Isoldi KK. Overweight and obesity: key components of cardiometabolic risk. Clin Cornerstone. 2007;8(3):29-37. [PubMed 18452840].

3. Gallagher EJ, LeRoith D. Insulin, insulin resistance, obesity, and cancer. Curr Diab Rep. 2010;10(2):93-100. doi: 10.1007/s11892-010-0101-y. [PubMed: 20425567].

4. Puhl RM, Latner JD. Stigma, obesity, and the health of the nation's children. Psychol Bull. 2007;133(4):557-80. doi: 10.1037/00332909.133.4.557. [PubMed: 17592956]. 
5. Tsiros MD, Olds T, Buckley JD, Grimshaw P, Brennan L, Walkley J, et al. Health-related quality of life in obese children and adolescents. Int J Obes (Lond). 2009;33(4):387-400. doi: 10.1038/ijo.2009.42. [PubMed: 19255583].

6. Engeland A, Bjorge T, Tverdal A, Sogaard AJ. Obesity in adolescence and adulthood and the risk of adult mortality. Epidemiology. 2004;15(1):79-85. doi: 10.1097/01.ede.0000100148.40711.59. [PubMed: 14712150].

7. Abtahi MJSA, Eshraghian M, Dorosti AR, Sadrzadeh Yeganeh H, Pouraram H. Overweight, obesity and some related socio-economic factors among adolescent girls in Tehran, Iran. Payesh. 2009;8(2):11322.

8. Morrissey TW. Trajectories of growth in body mass index across childhood: Associations with maternal and paternal employment. Soc Sci Med. 2013;95:60-8. doi: 10.1016/j.socscimed.2012.05.038. [PubMed: 22795914].

9. Doustmohammadian A, Abdollahi M, Bondarianzadeh D, Houshiar$\operatorname{rad} \mathrm{A}, \mathrm{Abtahi}$ M. Parental determinants of overweight and obesity in Iranian adolescents: a national study. Iran J Pediatr. 2012;22(1):35-42. [PubMed: 23056857].

10. Shrewsbury V, Wardle J. Socioeconomic status and adiposity in childhood: a systematic review of cross-sectional studies 1990-2005. Obesity (Silver Spring). 2008;16(2):275-84. doi: 10.1038/oby.2007.35. [PubMed: 18239633].

11. Anderson PM, Butcher KF, Levine PB. Maternal employment and overweight children.J Health Econ. 2003;22(3):477-504. doi: 10.1016/S01676296(03)00022-5. [PubMed: 12683963].

12. Etelson D, Brand DA, Patrick PA, Shirali A. Childhood obesity: do parents recognize this health risk?. Obes Res. 2003;11(11):1362-8. doi: 10.1038/oby.2003.184. [PubMed: 14627757].

13. Mamun AA, McDermott BM, O'Callaghan MJ, Najman JM, Williams GM. Predictors of maternal misclassifications of their offspring's weight status: a longitudinal study. Int J Obes (Lond). 2008;32(1):4854. doi:10.1038/sj.ijo.0803757. [PubMed:18193064].

14. Maynard LM, Galuska DA, Blanck HM, Serdula MK. Maternal perceptions of weight status of children. Pediatrics. 2003;111(5 Pt 2):1226-31. [PubMed: 12728143].

15. Shrewsbury VA, Garnett SP, Campbell K, Carver A, Torvaldsen S, Steinbeck KS, et al. Maternal misconceptions of weight status among Nepean adolescents. J Acad Nutr Diet. 2012;112(12):2007-13. doi: 10.1016/j.jand.2012.08.024. [PubMed: 23174687].

16. Zonana-Nacach A, Conde-Gaxiola ME. [Mothers' perception of their children's obesity]. Gac Med Mex. 2010;146(3):165-8. [PubMed: 20957811].

17. Hearst MO, Sherwood NE, Klein EG, Pasch KE, Lytle LA. Parental perceptions of their adolescent's weight status: the ECHO study. Am J Health Behav. 2011;35(2):248-55. [PubMed: 21204687].

18. Arcan C, Neumark-Sztainer D, Hannan P, van den Berg P, Story M, Larson N. Parental eating behaviours, home food environment and adolescent intakes of fruits, vegetables and dairy foods: longitudinal findings from Project EAT. Public Health Nutr. 2007;10(11):1257-65. doi: 10.1017/S1368980007687151. [PubMed: 17391551].

19. Beets MW, Cardinal BJ, Alderman BL. Parental social support and the physical activity-related behaviors of youth: a review. Health Educ Behav. 2010;37(5):621-44. doi: 10.1177/1090198110363884. [PubMed: 20729347].

20. Berge JM, Maclehose R, Loth KA, Eisenberg M, Bucchianeri MM, Neumark-Sztainer D. Parent conversations about healthful eating and weight: associations with adolescent disordered eating behaviors. JAMA Pediatr. 2013;167(8):746-53. doi: 10.1001/jamapediatrics.2013.78. [PubMed: 23797808].

21. Yao CA, Rhodes RE. Parental correlates in child and adolescent physical activity: a meta-analysis. Int J Behav Nutr Phys Act. 2015;12:10. doi: 10.1186/s12966-015-0163-y. [PubMed: 25890040].

22. Hosseini-Esfahani F, Mousavi Nasl Khameneh A, Mirmiran P, Ghan- barian A, Azizi F. Trends in risk factors for cardiovascular disease among Iranian adolescents: the Tehran Lipid and Glucose Study, 1999-2008. J Epidemiol. 2011;21(5):319-28. doi: 10.2188/jea.JE20100162. [PubMed: 21804294].

23. Golan M. Parents as agents of change in childhood obesity from research to practice. Int J Pediatr Obes. 2006;1(2):66-76.

24. Jalali-Farahani S, Chin YS, Amiri P, Mohd Taib MN. Body mass index (BMI)-for-age and health-related quality of life (HRQOL) among high school students in Tehran. Child Care Health Dev. 2014;40(5):731-9. doi: 10.1111/cch.12103. [PubMed: 23952615].

25. Mohammadpour-Ahranjani B, Rashidi A, Karandish M, Eshraghian MR, Kalantari N. Prevalence of overweight and obesity in adolescent Tehrani students, 2000-2001: an epidemic health problem. Public Health Nutr. 2004;7(5):645-8. [PubMed: 15251055].

26. Amini M, Omidvar N, Kimiagar M. Prevalence of overweight and obesity among junior high school students in a district of Tehran.J Res Med Sci. 2007;12(6):315-9.

27. Aljunaibi A, Abdulle A, Nagelkerke N. Parental weight perceptions: a cause for concern in the prevention and management of childhood obesity in the United Arab Emirates. PLoS One. 2013;8(3):59923. doi: 10.1371/journal.pone.0059923. [PubMed: 23555833].

28. Eckstein KC, Mikhail LM, Ariza AJ, Thomson JS, Millard SC, Binns HJ, et al. Parents' perceptions of their child's weight and health. Pediatrics. 2006;117(3):681-90. doi: 10.1542/peds.2005-0910. [PubMed: 16510647].

29. Hudson E, McGloin A, McConnon A. Parental weight (mis)perceptions: factors influencing parents' ability to correctly categorise their child's weight status. Matern Child Health J. 2012;16(9):1801-9. doi: 10.1007/s10995-011-0927-1. [PubMed: 22139047].

30. Doustmohammadian A, Dorostymotlagh AR, Keshavarz A, Sadrzadehyeganeh H, Mohammadpour-Ahrangani B. Socio-demographic Factors Associated with Body Mass Index of Female Adolescent Students in Semnan City, Iran. Malays J Nutr. 2009;15(1):27-35. [PubMed: 22691802].

31. Kelishadi R, Pour MH, Sarraf-Zadegan N, Sadry GH, Ansari R, Alikhassy $\mathrm{H}$, et al. Obesity and associated modifiable environmental factors in Iranian adolescents: Isfahan Healthy Heart Program - Heart Health Promotion from Childhood. Pediatr Int. 2003;45(4):435-42. [PubMed: 12911481].

32. Maddah M. Overweight and obesity among Iranian female adolescents in Rasht: more overweight in the lower social group. Public Health Nutr. 2007;10(5):450-3. doi: 10.1017/S1368980007219664. [PubMed: 17411464].

33. Maddah M, Nikooyeh B. Obesity among Iranian adolescent girls: location of residence and parental obesity. $J$ Health Popul Nutr. 2010;28(1):61-6.

34. Shafaghi K, Shariff ZM, Taib MN, Rahman HA, Mobarhan MG, Jabbari H. Parental body mass index is associated with adolescent overweight and obesity in Mashhad, Iran. Asia Pac J Clin Nutr. 2014;23(2):225-31. doi: 10.6133/apjcn.2014.23.2.11. [PubMed: 24901091].

35. Krahnstoever Davison K, Francis LA, Birch LL. Reexamining obesigenic families: parents' obesity-related behaviors predict girls' change in BMI. Obes Res. 2005;13(11):1980-90. doi: 10.1038/oby.2005.243. [PubMed: 16339130].

36. Binkin N, Spinelli A, Baglio G, Lamberti A. What is common becomes normal: the effect of obesity prevalence on maternal perception. Nutr Metab Cardiovasc Dis. 2013;23(5):410-6. doi: 10.1016/j.numecd.2011.09.006. [PubMed: 22212600].

37. Flores-Pe-aa Y, Avila-Alpirez H, Trejo-Ortiz PM, Ugarte-Esquiveld A, Cardenas-Villarreale VM, Gallegos-Martínez J. Homogeneity of maternal perception of her child's weight in Northeastern Mexico. Anthropologist. 2014;17(3):991-1001.

38. Pakpour AH, Yekaninejad MS, Chen H. Mothers' perception of obesity in schoolchildren: a survey and the impact of an educational intervention. J Pediatr (Rio J). 2011;87(2):169-74. [PubMed: 21503375] 